\title{
AP05
}

\section{Pre-Aruma Unconformity and Lower Aruma Channels in Eastern Saudi Arabia}

\author{
J. Farraday* (Saudi Aramco) \& W. Tan (Saudi Aramco)
}

\section{SUMMARY}

The channel-like features in the Lower Aruma Formation are observed. There may be a correlation between strong positive seismic reflectors and increase in porosity for the stacked carbonate reservoirs. Indepth study of hydrocarbon charge and migration pathway will help determine the overall potential of the Lower Aruma Formation in the oil and gas exploration. 
The focus of the abstract is the Pre-Aruma Unconformity (PAMU) and the petroleum system in the Aruma Formation. The topography of the Pre-Aruma Unconformity (PAMU) is the depositional foundation of the Aruma Formation in the Arabian Plate mega sequence AP9 and largely an angular unconformity that erodes into the Wasia Formation. The significant fall of the sea level at the end of the mega sequence AP8 caused the erosion of the Mishrif member of the Wasia Formation; in particular on paleo-structural highs. In some places, the erosion was so severe that it eroded away all three members including the Mishrif, Rumaila and the Ahmadi members from shallow to deep.

The Aruma Formation is a Late Cretaceous carbonate unit. It is bounded by two unconformities, PAMU on the bottom and Pre-Cenozoic Unconformity on top. When the sea level started to rise, the basal Aruma initial transgressive shale unit formed the top seal for the underlying reservoir in the Mishrif member. The lower portion of Aruma is comprised of the interbedded shale and grainstone, the middle portion rich in grainy facies, while the upper wackestone.

The Aruma Formation consists of two main carbonate reservoir units, the Lower and Upper Aruma reservoirs. The abstract focuses on the Lower Aruma reservoir which is characterized by a series of channel-like features. The straight shape of channels matches very few modern analogues. The exploration community has paid little attention to the channel-like features in terms of exploring potential stratigraphic traps related to the potential channels.

The lower Aruma shale and the tight carbonate in the overlying Umm Er Radhuma Formation play a role as a top seal for the Lower Aruma reservoir. Additional seal exists within AP10 near the base of the Dammam Formation (i. e., Midra and Saila shale members). The Aruma is believed to be charged by the source rock from the Sulaiy Formation and its equivalent rocks basinward. 